\title{
Nanopatterned Silicon Substrate Use in Heterojunction Thin Film Solar Cells Made by Magnetron Sputtering
}

\author{
Shao-Ze Tseng, ${ }^{1}$ Chang-Rong Lin, ${ }^{2}$ Hung-Sen Wei, ${ }^{1}$ \\ Chia-Hua Chan, ${ }^{2}$ and Sheng-Hui Chen ${ }^{1}$ \\ ${ }^{1}$ Department of Optics and Photonics, National Central University, 300 Chung-Da Road, Chungli 32001, Taiwan \\ ${ }^{2}$ Graduate Institute of Energy Engineering, National Central University, 300 Chung-Da Road, Chungli 32001, Taiwan \\ Correspondence should be addressed to Chia-Hua Chan; hua0121.tw@yahoo.com.tw
}

Received 16 April 2014; Accepted 18 May 2014; Published 15 June 2014

Academic Editor: Viktor Brus

Copyright (C) 2014 Shao-Ze Tseng et al. This is an open access article distributed under the Creative Commons Attribution License, which permits unrestricted use, distribution, and reproduction in any medium, provided the original work is properly cited.

This paper describes a method for fabricating silicon heterojunction thin film solar cells with an ITO/p-type a-Si:H/n-type cSi structure by radiofrequency magnetron sputtering. A short-circuit current density and efficiency of $28.80 \mathrm{~mA} / \mathrm{cm}^{2}$ and $8.67 \%$ were achieved. Novel nanopatterned silicon wafers for use in cells are presented. Improved heterojunction cells are formed on a nanopatterned silicon substrate that is prepared with a self-assembled monolayer of $\mathrm{SiO}_{2}$ nanospheres with a diameter of $550 \mathrm{~nm}$ used as an etching mask. The efficiency of the nanopattern silicon substrate heterojunction cells was $31.49 \%$ greater than that of heterojunction cells on a flat silicon wafer.

\section{Introduction}

More energy is consumed as technology advances. Therefore, the discovery and development of new energy sources have become global issues. In response to global environmental problems, many countries have begun research into green power, including tidal power, wind power, geothermal power, and solar power. Solar energy provides a promising means of satisfying the growing demand for energy, and the development of lower cost and higher efficiency solar cells is being pursued. Silicon-based solar cells account for the largest single share of the photovoltaic market.

Nontandem amorphous silicon (a-Si) thin film solar cells and conventional diffused monocrystalline silicon (c-Si) solar cells are compared herein. The a-Si devices have a higher open-circuit voltage $\left(V_{\text {oc }}\right)$ and higher energy band gap. However, the conversion efficiency of a-Si devices is lower than that of $\mathrm{c}$-Si devices, because a-Si devices have a narrow range of absorption wavelengths and suffer from photodegradation [1]. In 1992, Sanyo developed a new a-Si/c-Si heterojunction solar cell structure, called HIT (heterojunction with intrinsic thin film), using plasma-enhanced chemical vapor deposition (PECVD) [2]. This structure was newly developed for Sibased solar cells. HIT solar cells have the following three advantages [3, 4]: (1) high-quality a-Si films that exhibit excellent surface passivation and favorable $p-n$ junction properties, (2) a low processing temperature, and (3) better thermal stability and higher $V_{o c}$ than conventional c-Si solar cells [5]. Most corporations and research institutes use chemical vapor deposition (CVD) methods to prepare a-Si thin films [6-8]. This method has several advantages, including favorable step coverage, the formation of a film of high density owing to the few pinholes and voids formed, and a high deposition rate, but it also has some shortcomings, such as expensive equipment costs, contamination of chemical particles, and the use of extremely toxic gases such as $\mathrm{SiH}_{4}$, $\mathrm{B}_{2} \mathrm{H}_{6}$, and $\mathrm{PH}_{3}$ in the CVD deposition process, which may result in problems of industrial safety and environmental pollution. In contrast, the physical vapor deposition (PVD) method has many advantages, such as nontoxicity, better process control, and lower cost. Therefore, the PVD method was used herein to investigate Si-based heterojunction thin film solar cells.

Sputtering high quality doped/un-doped a-Si films is difficult. The difficulties are that (1) ion bombardment is likely to form an unwanted microstructure in the thin films, reducing their quality, and (2) the PVD processes have 
a low doping efficiency, so the number of doping atoms in the sputtering deposition processes should be increased to achieve the same degree of doping as in doped a-Si films that are formed by CVD. Therefore, some research is being performed under way to improve the quality of doped a-Si thin films that are formed by sputtering. In 2001, Ohmura et al. sputtered p-type a-Si films with extra boron grains on a silicon wafer to obtain more dopant boron atoms [9]. In 2002, De Lima et al. deposited p-type a-Si films with extra boron grains by sputtering a Si target; the sputtering increased the number of boron dopant atoms in the p-type a-Si films, yielding the same conductivity as that of a-Si films that are formed by CVD [10].

The reflectance of polished silicon wafers is about $36 \%$ at visible wavelengths. Therefore, a simple and powerful way to improve the efficiency of solar cells that are made by sputtering is to increase the number of absorbed photons to increase the photocurrent. Many methods can effectively reduce the Fresnel reflection of silicon-based optical components, such as the application of antireflection coatings (ARCs) [11, 12] and roughening of the surface. A single-layered antireflection thin film can only reflect particular wavelengths, whereas a multilayer coating is more effective for reflecting a broad range of wavelengths. Unfortunately, ARCs are made from limited materials and they suffer from such shortcomings as thermal mismatch, which is caused by lamination, and the need for expensive and complicated equipment to fabricate them.

Surface roughening is used in various applications, for example, LEDs [13, 14], MENS devices, and solar cells [15-19]. As more advanced fabrication methods have been developed, periodic antireflection structures have attracted increasing interest. Moth-eye antireflection structures are the most well-known $[20,21]$. Periodic structures can generally be divided into microstructures and nanostructures based on their critical dimension. Various techniques can be used to fabricate and pattern a nanostructure substrate, including E-beam lithography, nanoimprint lithography [22, 23], holographic lithography [24], nanosphere lithography [25-28], and chemical wet etching [29-31]. In the present authors' previous study, a nanoscale patterned sapphire substrate was used to improve the light extraction efficiency of LEDs [32]. The same approach can be used to develop silicon-based devices such as solar cells and optical sensors. Therefore, nanoscale structures can be simply and effectively used to reduce Fresnel reflection from the silicon surface.

In this work, a uniform and periodic nanopattern silicon substrate (NPSiS) was fabricated by the self-assembly of a monolayer array of nanospheres, which was followed by inductively coupled plasma (ICP) dry etching to translate a $2 \mathrm{D}$ periodic pattern on the silicon wafer. The ICP etching time was tuned to fabricate NPSiS structures of four depths. Then, these variously textured wafers were used on Sibased heterojunction thin-film (HJT) solar cells, which were fabricated using a radiofrequency $(\mathrm{RF})$ magnetron sputtering cluster system. The consequent improvement in NPSiS HJT solar cells was investigated.

\section{Experimental}

2.1. Reflectance Spectra Simulation. To obtain NPSiS with excellent antireflection properties, the size of the textured structure must be within the subwavelength range. Welldesigned periodic nanostructures exhibit a gradually changing refractive index, which can be used to maximize the omnidirectional antireflection character of NPSiS over a wide range of wavelengths. In this work, NPSiS structures were simulated and the three-dimensional (3D) finite-difference time-domain (FDTD) method (Lumerical Solutions, Inc.) was used to optimize their period and geometry. The size of the nanostructures for use in silicon solar cells must be less than $850 \mathrm{~nm}$. Based on the results of an NPSiS simulation, the period of the nanostructures was designed to be $550 \mathrm{~nm}$ with periodic boundaries. With the NPSiS period set, other NPSiS structural parameters - top width (TW), bottom width (BW), and etching depth (D) - were simulated. Plane waves with wavelengths of $350 \mathrm{~nm}$ to $950 \mathrm{~nm}$ were normally incident on the structures.

2.2. Patterning Silicon Wafer. Highly uniform subwavelength $\mathrm{SiO}_{2}$ nanospheres were prepared using the modified Stober process and an alcohol-rich phase. Purified water, ammonium hydroxide, and pure alcohol were added to a sealed bottle that was purged with nitrogen. The contents were stirred to ensure that they were thoroughly mixed. Tetraethyl orthosilicate (TEOS) was then added to the system. After two hours of stirring, the latex was centrifuged to collect the $550 \mathrm{~nm} \mathrm{SiO}{ }_{2}$ nanospheres, which were washed three times with pure alcohol to remove any remaining impurities.

Figure 1 shows the flow chart of the preparation of NPSiS. First, the silicon wafer was immersed in latex that comprised $\mathrm{SiO}_{2}$ nanospheres with a diameter of $550 \mathrm{~nm}$. Next, a monolayer of nanospheres was arrayed on the surface of the silicon by the dip-coating method. The silicon substrate was a CZ n-type c-Si (100) wafer with a base resistivity of 1$10 \Omega \cdot \mathrm{cm}$, and its thickness was about $325 \mu \mathrm{m}$. After the $\mathrm{SiO}_{2}$ nanospheres were arrayed on the wafer, they were used as the etching mask in the ICP process in which the NPSiS was fabricated. The ICP process involved the well-mixed gases $\mathrm{BCl}_{3}, \mathrm{Cl}_{2}$, and $\mathrm{Ar}$ with a reactor pressure of $7.5 \mathrm{mTorr}$, a top electrode RF power of $300 \mathrm{~W}$, a bottom electrode RF power of $116 \mathrm{~W}$, and a bias voltage of $210 \mathrm{~V}$.

2.3. Deposition of Thin Films. The first step in the fabrication of the p-type a-Si:H thin films and the deposition of the transparent conductive oxide (TCO) layer was RCA cleaning. The native oxide layer on the surface of the $\mathrm{Si}$ wafer was removed using diluted HF (2\%) solution for $120 \mathrm{~s}$ before the p-type a-Si:H thin film was deposited. The p-type a$\mathrm{Si}: \mathrm{H}$ thin films and TCO layer were deposited using a radiofrequency (RF, $13.56 \mathrm{MHz}$ ) magnetron sputtering cluster system. In the deposition of the p-type a-Si: $\mathrm{H}$ thin films, the sputtering target was a p-type Si disc with a diameter of $3^{\prime \prime}$, and some boron (B) grains were placed on the p-type $\mathrm{Si}$ target to increase the doping; the area of boron was about $30 \%$ of the area of the plasma ring of the target. 


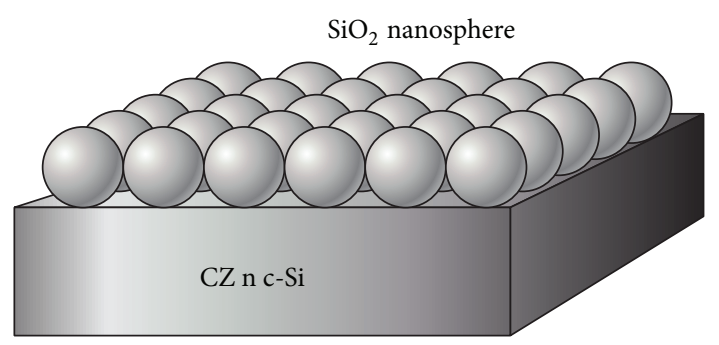

(a)

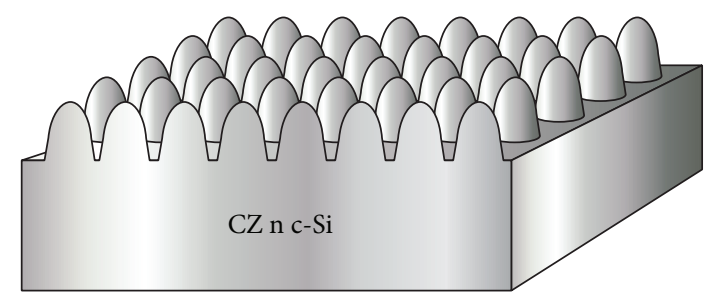

(b)

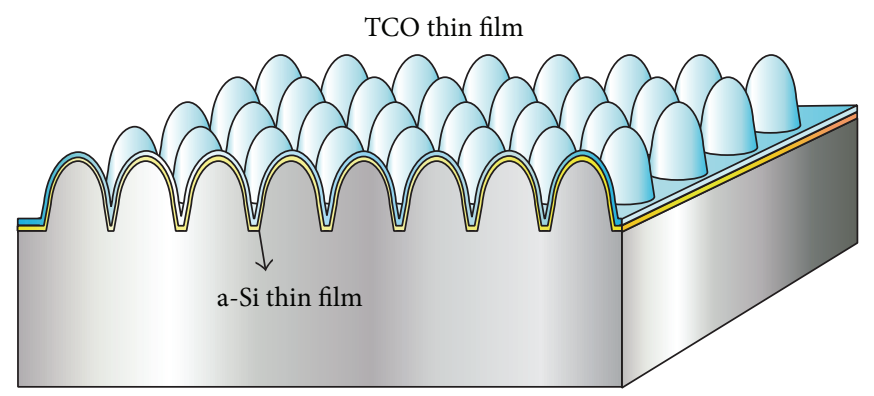

(c)

FIGURE 1: Flow chart of preparation of NPSiS HJT solar cells; (a) coating monolayer of $\mathrm{SiO}_{2}$ nanospheres on CZ n-type c-Si substrate; (b) using $\mathrm{SiO}_{2}$ nanospheres as etching mask in ICP process to fabricate NPSiS; (c) depositing the p-type a-Si : $\mathrm{H}$ thin films and TCO thin films by RF magnetron sputtering.

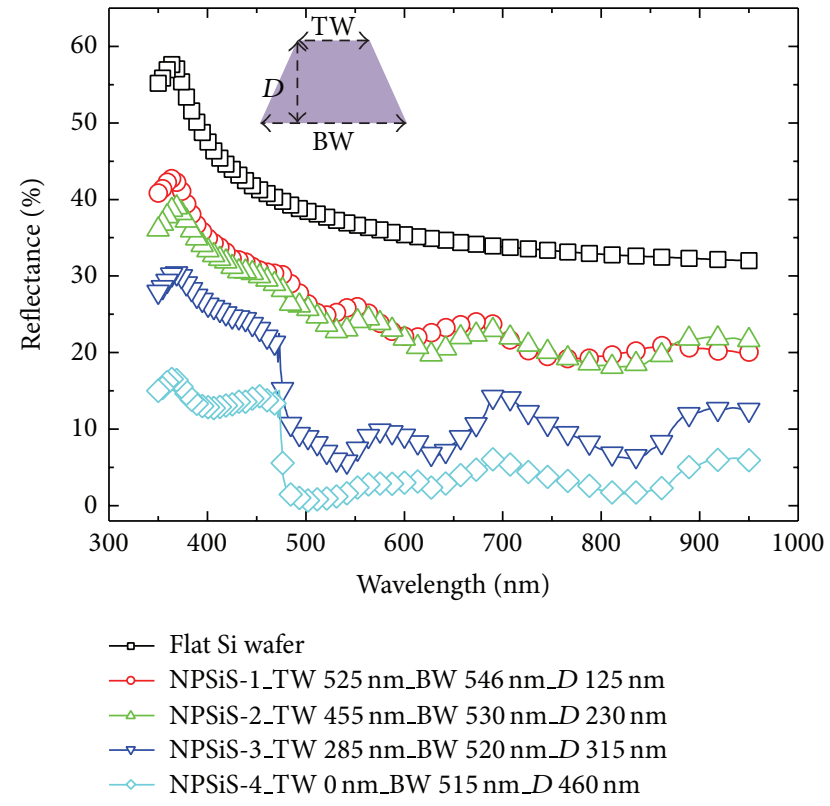

FIGURE 2: Using 3D-FDTD method to simulate reflectance spectra of periodic $550 \mathrm{~nm}$ NPSiS.

The p-type a-Si : $\mathrm{H}$ films were deposited at an RF power of $100 \mathrm{~W}$ under argon and hydrogen as working gases with a $\mathrm{P}_{\mathrm{H} 2} / \mathrm{P}_{\text {Ar }}$ partial pressure ratio set to three. The temperature of the chamber was 300 degrees Celsius. The base pressure and working pressure of the chamber were less than $5.0 \times 10^{-6}$ torr and $2.1 \times 10^{-3}$ torr, respectively. The thickness of the p-type a-Si : $\mathrm{H}$ thin film was $10 \mathrm{~nm}$. Following the deposition of the p-type a-Si : $\mathrm{H}$ thin films, the samples were moved to another chamber to deposit the TCO layer. During transportation, each sample was kept in a vacuum to prevent oxidation, which could have increased the number of defects in the silicon thin film. Indium tin oxide (ITO) films were used as the TCO layer. Two ITO layers were deposited on the p-type a-Si : $\mathrm{H}$ films; the first layer was an ITO : $\mathrm{O}_{2}$ film that raised the work function to increase the $V_{\text {oc }}$ of the silicon HJT solar cells. The thickness of the ITO: $\mathrm{O}_{2}$ film that was deposited at an RF power of $100 \mathrm{~W}$ and a chamber temperature of 300 degrees Celsius was $20 \mathrm{~nm}$. The working gases were argon, which flowed at 10 standard cubic centimeters per minute (SCCM), and oxygen, which flowed at 0.9 SCCM. Following the deposition of the ITO : $\mathrm{O}_{2}$ film, the $80 \mathrm{~nm}$ thick ITO film without oxygen gas was deposited on the ITO: $\mathrm{O}_{2}$ film. The two layers of ITO film increased the $V_{\text {oc }}$ of the HJT cells and maintained favorable conductivity of the TCO layer $[33,34]$.

The last step of the fabrication of silicon HJT solar cells is coating both of the front (with a finger separation of $1.9 \mathrm{~mm}$ and a width $100 \mu \mathrm{m}$ ) and rear metal electrodes with titanium (Ti) to a thickness of $20 \mathrm{~nm}$ and then aluminum (Al) to a thickness of 1 1.2 $\mu \mathrm{m}$ using an e-gun evaporator. The performance of the solar cell thus formed was determined by making $I-V$ measurements in the dark and under illumination (AM 1.5G condition, $100 \mathrm{~mW} / \mathrm{cm}^{2}$ ).

\section{Results and Discussion}

3D-FDTD calculations were performed to simulate the optical behavior of the NPSiS wafer [35, 36]. Figure 2 shows the reflectance spectra of the flat silicon wafer and four NPSiS wafer. The curve through the black symbols represents 


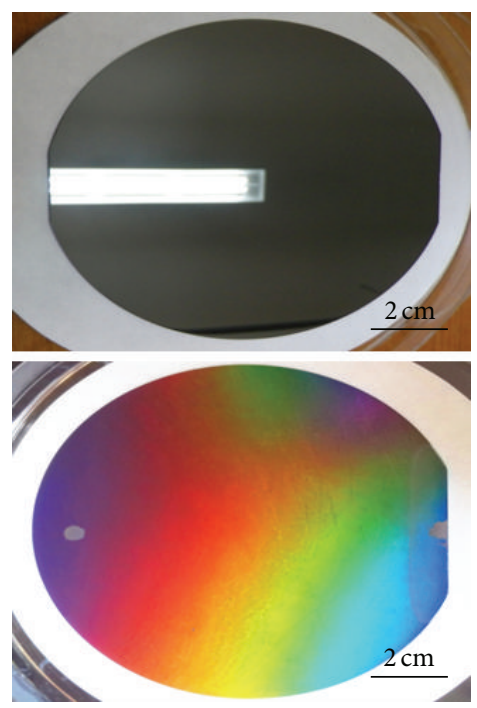

(a)
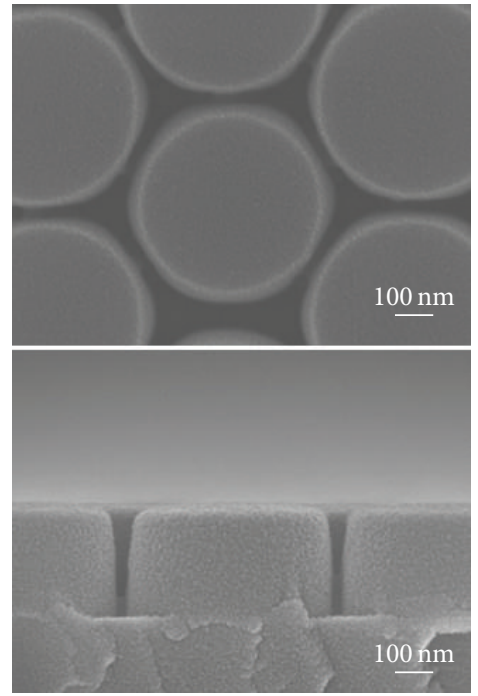

(d)

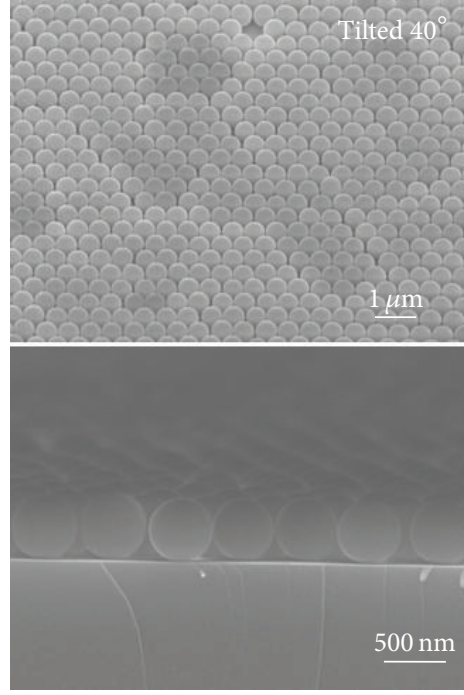

(b)
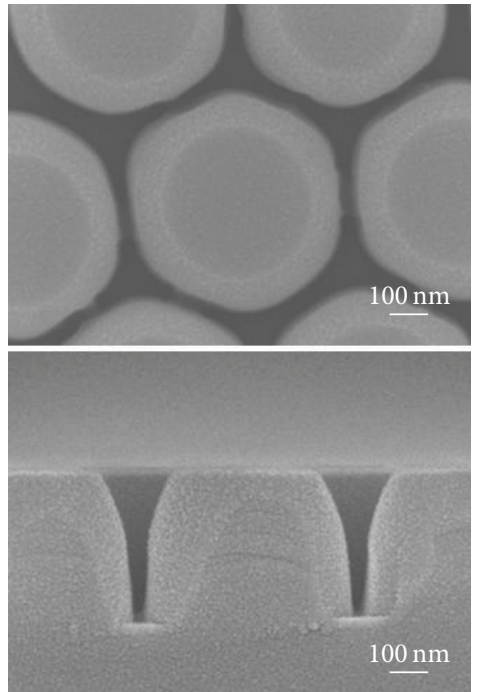

(e)

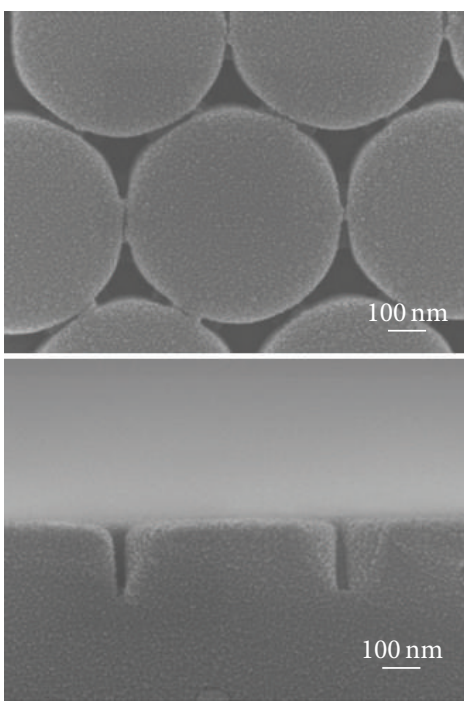

(c)
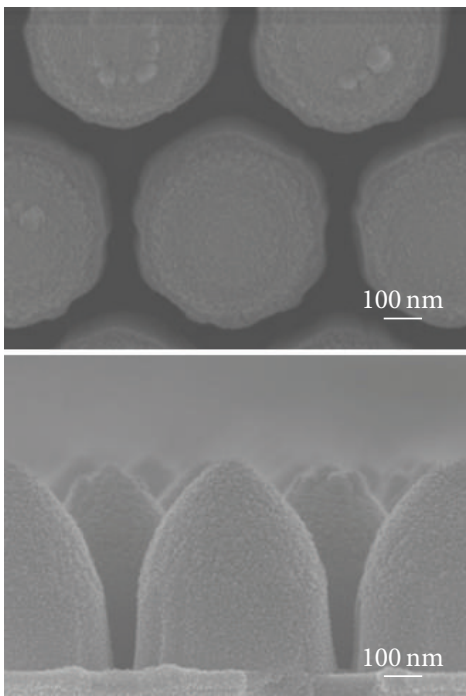

(f)

FIGURE 3: (a) Photograph of $4^{\prime \prime}$ bulk silicon wafer (top) and a monolayer array of $550 \mathrm{~nm}$ nanospheres that were deposited on a 4 inch silicon wafer (bottom). (b) Close view of a monolayer nanosphere on Si wafer; ((c)-(f)) NPSiS with different dry etching times: (c) NPSiS-1, 80 s (depth: $180 \mathrm{~nm}$ ), (d) NPSiS-2, $150 \mathrm{~s}$ (depth: $270 \mathrm{~nm}$ ), (e) NPSiS-3, $230 \mathrm{~s}$ (depth: $370 \mathrm{~nm}$ ), and (f) NPSiS-4, $450 \mathrm{~s}$ (depth: $550 \mathrm{~nm}$ ).

the simulated reflectance of the flat silicon wafer; the average reflectance at wavelengths from $350 \mathrm{~nm}$ to $950 \mathrm{~nm}$ is about $41 \%$. The curves through the red, blue, pink, and green symbols plot the simulated reflectances of NPSiS-1, NPSiS-2, NPSiS-3, and NPSiS- 4 , which have average values of $28.42 \%$, $26.99 \%, 16.41 \%$, and $7.59 \%$, respectively. The NPSiS- 4 exhibits the best reduction of reflectance by the multireflection of the normally incident light.

The reflectance spectra that were obtained by the 3DFDTD simulation demonstrate that the pointed NPSiS exhibited better antireflection properties than the frustum NPSiS. Since multireflection efficiently increased the absorption of light by the pointed NPSiS wafer, it reduced the reflectance. As the results of the simulation reveal, NPSiS with a deeper frustum shape exhibited a stronger antireflection effect, revealing that the depth of the textured silicon structures affected its reflectance.

Based on the results of the simulation, the ICP dry etching recipes can be modified to fabricate various NPSiS wafer. Figure 3(a) presents the monolayer array of $550 \mathrm{~nm}$ nanospheres that were deposited on a 4 inch silicon substrate; the diffractive nature of the nanospheres is evident. The scanning electron microscopic (SEM) image in Figure 3(b) provides a close view of a monolayer of nanospheres, revealing their hexagonal arrangement; the side-view SEM image of the arrangement of nanospheres confirms the monolayer arrangement. Owing to the success of the aforementioned deposition process, the $550 \mathrm{~nm}$ nanospheres were used in the 


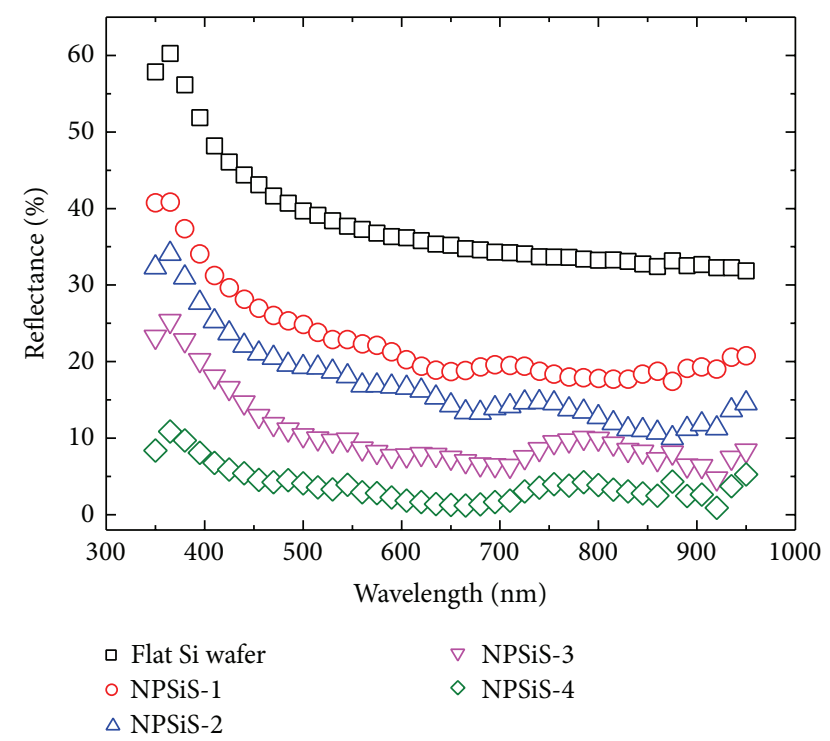

FIGURE 4: Reflectance spectra of flat c-Si wafer and NPSiS wafers obtained using integrated sphere system.

rest of this work. Figures 3(c) to 3(f) were obtained after etching times of $80 \mathrm{~s}$ (NPSiS-1), $150 \mathrm{~s}$ (NPSiS-2), $230 \mathrm{~s}$ (NPSiS3 ), and $450 \mathrm{~s}$ (NPSiS-4), and the resulting depths of the four textured wafers were about $180 \mathrm{~nm}, 270 \mathrm{~nm}, 370 \mathrm{~nm}$, and $550 \mathrm{~nm}$, respectively. Gradually increasing the etching time reduced the diameter of the $\mathrm{SiO}_{2}$ nanospheres and gradually reduced the top diameter of the frustum nanostructure until the nanosphere mask that had the shape of the NPSiS structure was overetched and so changed from a frustum shape to a bullet shape; its depth was limited to about $550 \mathrm{~nm}$.

Figure 4 shows the reflectance spectra of flat c-Si wafer and NPSiS wafers that were obtained using the integrated sphere system with an angle of incidence of light of $8^{\circ}$, in a wavelength range from $350 \mathrm{~nm}$ to $950 \mathrm{~nm}$. The curve through the black symbols reveals that the flat silicon wafer has an average reflectance of $37.96 \%$; the curves through the red, blue, pink, and green symbols provide the measured reflectance results for NPSiS-1, NPSiS-2, NPSiS-3, and NPSiS4 , which have average reflectance values of $22.62 \%, 16.89 \%$, $10.21 \%$, and $3.64 \%$, respectively. The measurements demonstrate that the total reflectance of NPSiS decreases as its depth increases, and the antireflective properties of all NPSiS wafers are evident not only in a particular range of wavelengths but also in the full range of wavelengths over which silicon absorbs region. The gradient of the refractive index of the nanostructure of the Si wafer surface can effectively reduce the Fresnel reflection of photons of short wavelengths $(<550 \mathrm{~nm})$. For long wavelength photons $(>700 \mathrm{~nm})$, the effective refractive index of the nanostructure as a porous layer between the Si wafer and air is a discontinuity of the refractive index, increasing the absorption of incident photons [37].

Figures 5(a) to 5(d) presented side-view SEM images of the NPSiS wafer following magnetron sputtering deposition. As shown in Figures 5(a)-5(d), the low step coverage that was achieved using the sputter coating process yielded different thicknesses of the covering ITO thin films on the top and side of the nanostructure. However, even though the step coverage that was achieved by sputtering is not very uniform, the ITO films and the p-type a-Si film both nevertheless formed a continuous layer, as shown in Figures 5(a)-5(d). Moreover, the nonuniform ITO films formed a layer with a gradient in the refractive index, which enhanced the antireflection effect of the NPSiS cells, as presented in Figure 5(e).

To discuss the omnidirectional antireflection effect, the angle-resolved integrated sphere system was used to measure the average reflectance of NPSiS wafers in HJT cells when light was incident at various angles. Figures 6(a) and 6(b) show the average reflectance that was achieved with light at angles of incidence from $8^{\circ}$ to $60^{\circ}$. The reflectance of NPSiS- 4 wafers was less than $12 \%$ for all angles of incidence, and the NPSiS-4 HJT cell devices exhibited the strongest omnidirectional antireflection effect of all NPSiS HJT cells, with a reflectance of less than $6 \%$ for all angles of incidence at wavelengths between $350 \mathrm{~nm}$ and $950 \mathrm{~nm}$. The above results demonstrate that the depth of NPSiS was $550 \mathrm{~nm}$ and the profile became bullet-shaped, and then its reflectance was nearly omnidirectional. Figure 6(c) presents a photograph of the reference HJT cell and the NPSiS HJT cells. As the depth of NPSiS increased, the outward appearance of the NPSiS HJT cell became more like that of a dark solar cell.

To analyze further the optical properties of NPSiS HJT cells, Figure 5(e) shows the reflectance spectra of NPSiS HJT cells and a nontextured HJT cell when light at wavelengths between $350 \mathrm{~nm}$ and $950 \mathrm{~nm}$ was normally incident. The curve through the black symbols reveals that the nontextured HJT cell had an average reflectance of $14.80 \%$. The curves through the red, blue, pink, and green symbols represent the measured reflectances of the NPSiS-1, NPSiS-2, NPSiS3 , and NPSiS-4 HJT cells, which had average reflectance values of $10.75 \%, 9.28 \%, 6.18 \%$, and $2.04 \%$, respectively. The purple dashed curve represents the reflectance of the $100 \mathrm{~nm}$ thick ITO layer on a glass substrate (B270). Based on the conductivity and work function of the TCO layer, the antireflection wavelength of the TCO layer on the silicon wafer was designed to be about $780 \mathrm{~nm}$, and its average absorption was about $3.4 \%$ at wavelengths from $350 \mathrm{~nm}$ to $950 \mathrm{~nm}$. In this TCO design, the reflectance of the nontextured silicon HJT cells exhibited a peak at a wavelength close to $500 \mathrm{~nm}$, at which wavelength the external quantum efficiency (EQE) of nontextured silicon HJT cell was reduced, as shown in Figure 7(c). However, the designed TCO layer increased the transmittance of incident light, increasing the $\mathrm{EQE}$ of the nontextured $\mathrm{HJT}$ cell to $75.5 \%$ at a wavelength of $400 \mathrm{~nm}$.

To investigate the electrical properties of HJT solar cells, the EQE, dark current-voltage $(I-V)$, and illuminated $I-V$ properties under a simulated AM1.5G condition at room temperature were measured. The EQE measurements yield the photon conversion efficiency of HJT cells at wavelengths from $300 \mathrm{~nm}$ to $1100 \mathrm{~nm}$ in steps of $10 \mathrm{~nm}$; the dark $I-V$ results are related to the characteristics of the interface between the p-type a-Si:H thin films and the n-type c-Si substrates in the HJT cells, and the illuminated $I-V$ measurements yield 


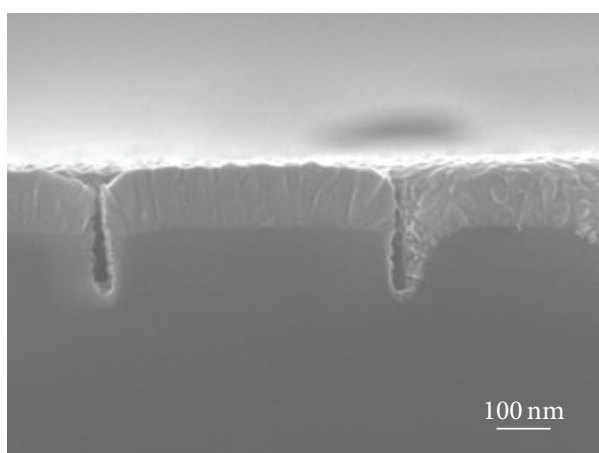

(a)

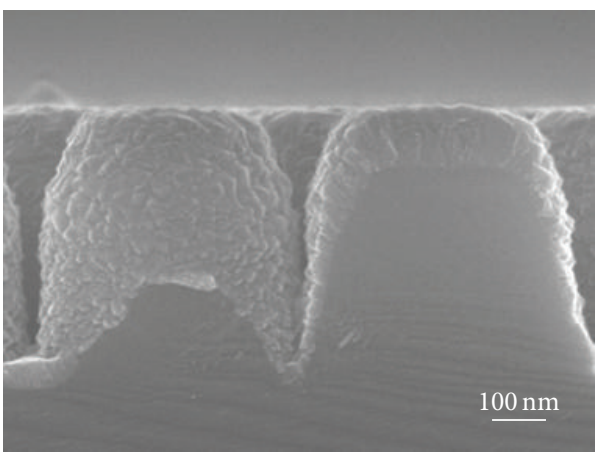

(c)

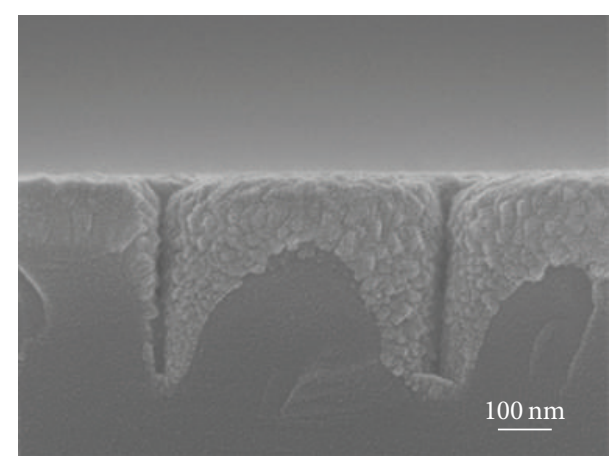

(b)

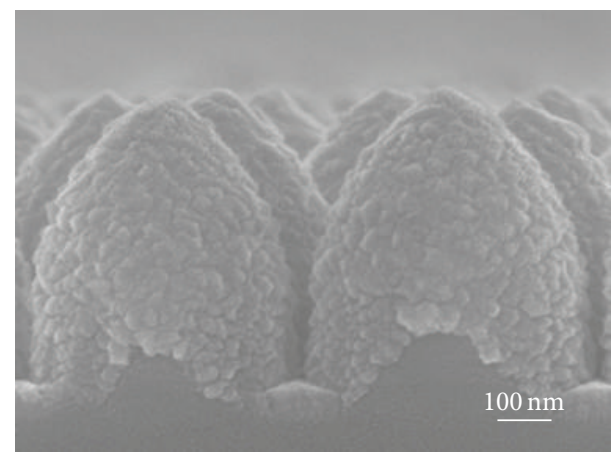

(d)

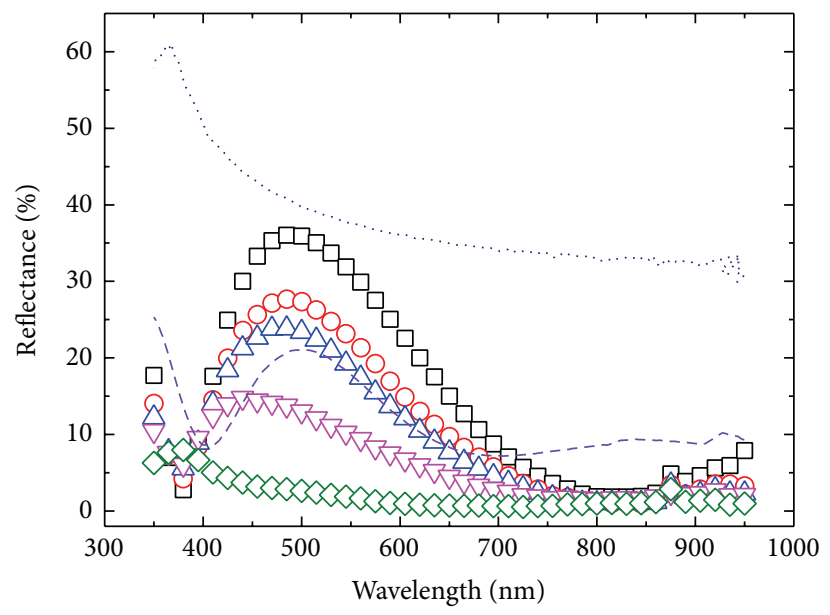

$\begin{array}{lll}\square \text { Nontextured HJT cell } & \diamond \text { NPSiS-4 HJT cell } \\ \bigcirc \text { NPSiS-1 HJT cell } & \text {..... Flat Si wafer } \\ \triangle \text { NPSiS-2 HJT cell } & --- \text { ITO } 100 \mathrm{~nm} \\ \nabla \text { NPSiS-3 HJT cell } & \end{array}$

(e)

FIgURE 5: Side-view SEM images of NPSiS wafer following magnetron sputtering deposition on four NPSiS wafers. (a) NPSiS-1 HJT cell, (b) NPSiS-2 HJT cell, (c) NPSiS-3 HJT cell, (d) NPSiS-4 HJT cell, and (e) reflectance spectra of NPSiS HJT cells and nontextured HJT cell.

the $V_{\text {oc }}$, short current density $\left(J_{\mathrm{sc}}\right)$, fill-factor $(\mathrm{FF})$, and power conversion efficiency of the HJT solar cells.

Figure 5(e) reveals that deeper NPSiS (1-4) HJT cells have a lower reflectance at a wavelength of $500 \mathrm{~nm}$, so the $J_{\mathrm{sc}}$ values that are calculated from the measured EQE vary from $26.65 \mathrm{~mA} / \mathrm{cm}^{2}$ for the nontextured HJT cell to $30.81 \mathrm{~mA} / \mathrm{cm}^{2}$ for the NPSiS-1 HJT cell, $31.40 \mathrm{~mA} / \mathrm{cm}^{2}$ for the NPSiS-2 HJT cell, $33.08 \mathrm{~mA} / \mathrm{cm}^{2}$ for the NPSiS-3 HJT cell, and $35.22 \mathrm{~mA} / \mathrm{cm}^{2}$ for the NPSiS4 HJT cell, as presented in Figure $7(\mathrm{c})$. These results demonstrate that the four NPSiS HJT cells exhibit differently enhanced EQE; in particular, in the NPSiS-4 HJT, the region of reduced EQE was completely repaired owing to the TCO layer, and its $J_{\text {sc }}$ reached $35.22 \mathrm{~mA} / \mathrm{cm}^{2}$.

Figure 7 (a) plots the measured dark $I-V$ results that were obtained with injected voltages from $-0.8 \mathrm{~V}$ to $+0.8 \mathrm{~V}$. The 


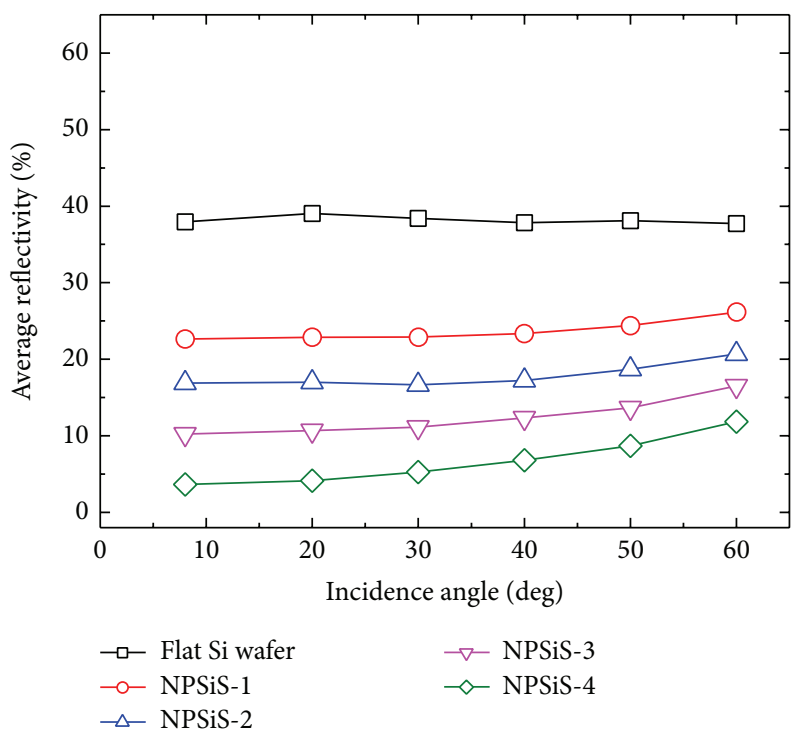

(a)

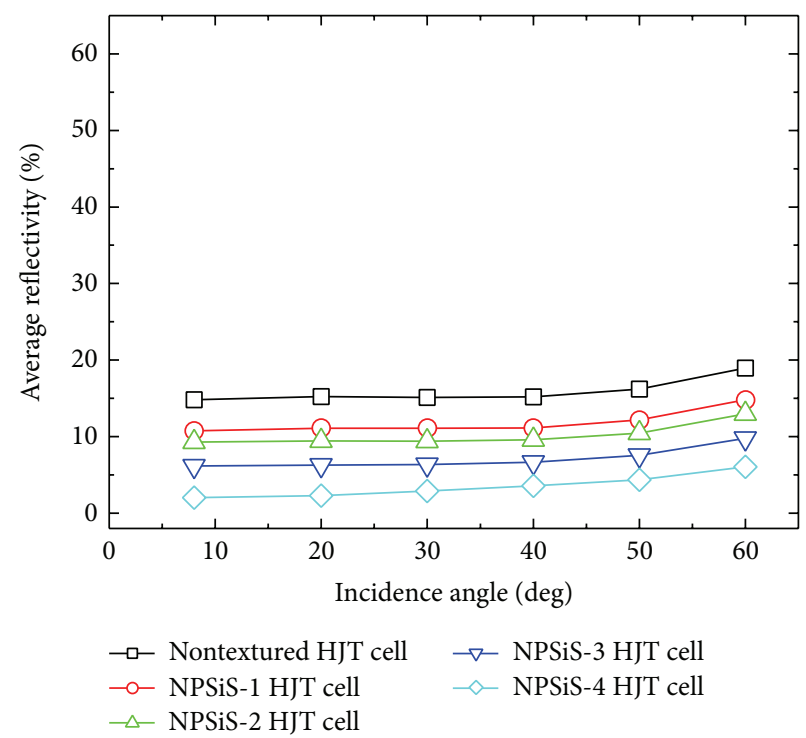

(b)

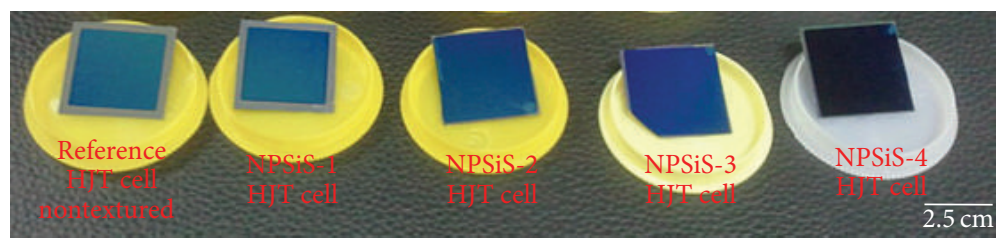

(c)

FIGURE 6: Average reflectance results achieved with light at angles of incidence from 8 degrees to 60 degrees at wavelengths between $350 \mathrm{~nm}$ and $950 \mathrm{~nm}$; (a) flat Si wafer and NPSiS wafer, (b) nontextured HJT cell and four NPSiS HJT cells, and (c) photograph of reference HJT cell and NPSiS HJT cells.

TABLE 1: $I-V$ characteristics of four NPSiS HJT cells and nontextured reference HJT cell.

\begin{tabular}{lcccccccc}
\hline & $\begin{array}{c}\text { Reflectance at } \\
500 \mathrm{~nm}(\%)\end{array}$ & $\begin{array}{c}\text { Designated } \\
\text { areas }\left(\mathrm{cm}^{2}\right)\end{array}$ & $V_{\mathrm{oc}}(\mathrm{mV})$ & $J_{\mathrm{sc}}\left(\mathrm{mA} / \mathrm{cm}^{2}\right)$ & FF $(\%)$ & Eff $(\%)$ & $\begin{array}{c}\text { Enhancement } \\
(\%)\end{array}$ & Rs $\left(\Omega\right.$-cm $\left.{ }^{2}\right)$ \\
\hline Nontextured & 35.91 & 0.76 & 537.69 & 28.80 & 56.30 & 8.67 & - & 9.61 \\
NPSiS-1 & 27.33 & 0.68 & 461.84 & 31.42 & 68.90 & 9.99 & 15.22 & 3.08 \\
NPSiS-2 & 23.38 & 0.76 & 434.89 & 32.26 & 65.00 & 9.12 & 5.19 & 3.07 \\
NPSiS-3 & 12.99 & 0.79 & 442.96 & 33.70 & 66.50 & 9.93 & 14.53 & 2.54 \\
NPSiS-4 & 2.64 & 0.71 & 481.94 & 36.20 & 65.20 & 11.40 & 31.49 & 2.68 \\
\hline
\end{tabular}

left-most curve in Figure 7(a) shows that the leakage currents of NPSiS HJT cells of various depths all exceeded those of the nontextured HJT cell. The right-hand side of Figure 7(a) reveals that generation-recombination currents of the four NPSiS HJT cells at less than the threshold voltage all exceeded those of the nontextured HJT cell, implying that the junctions in the four NPSiS HJT cells contained more defects than those of the nontextured cell [38].

The above results follow mostly from the fact that the ICP dry etching process damages the NPSiS surface, so more defects are generated in that surface than in the surface of the nontextured Si wafer. Figure 7(b) compares the illuminated $I$ $V$ characteristics of HJT solar cells with an NPSiS wafer with those of a cell with a flat silicon wafer. Table 1 also summarizes these characteristics. In Figure 7(b), the $J_{\text {sc }}$ of the NPSiS-4
HJT cell is $36.20 \mathrm{~mA} / \mathrm{cm}^{2}$, and its efficiency is $11.4 \%$, which is $31.49 \%$ greater than that, $8.67 \%$, of the nontextured HJT cell (Table 1). This result is consistent with the reflectance that was obtained using the integrating sphere system (Figures 5(a) and $5(\mathrm{~b})$ ), indicating that the lower reflectance of NPSiS is associated with the absorption of more photons, so the NPSiS HJT cells have a higher $J_{\text {sc }}$.

All NPSiS HJT cells exhibited an improved FF, because NPSiS increased the surface contact areas (as presented in Figure 8), reducing the resistivity of the HJT cells, causing the series resistivity of all the NPSiS-HJT cells to be lower than that of the nontextured HJT cell and the FF of the NPSiSHJT cells to be higher. However, the FF of NPSiS cannot grow steadily with the surface area being increased, because the dry etching processes damage the surface of the NPSiS 


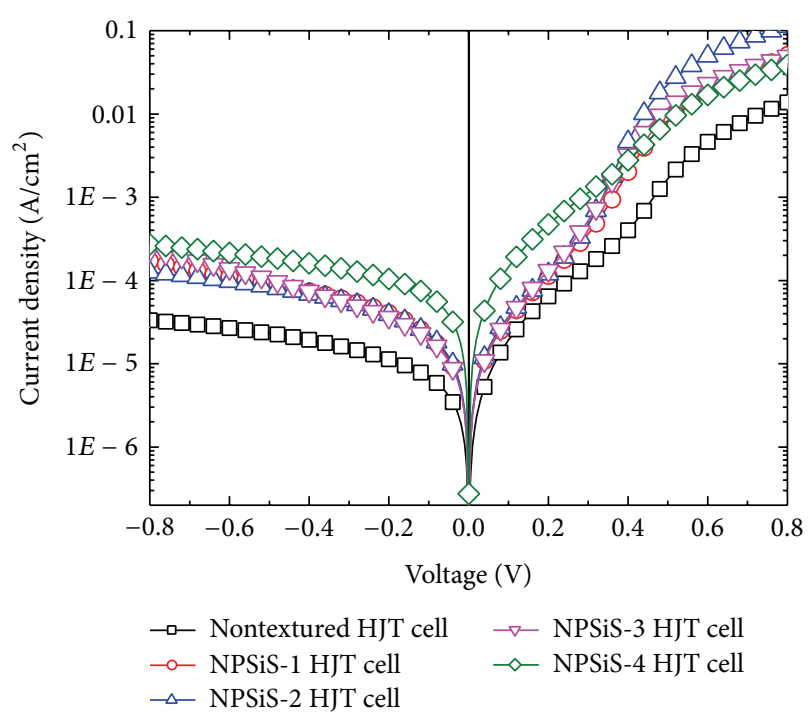

(a)

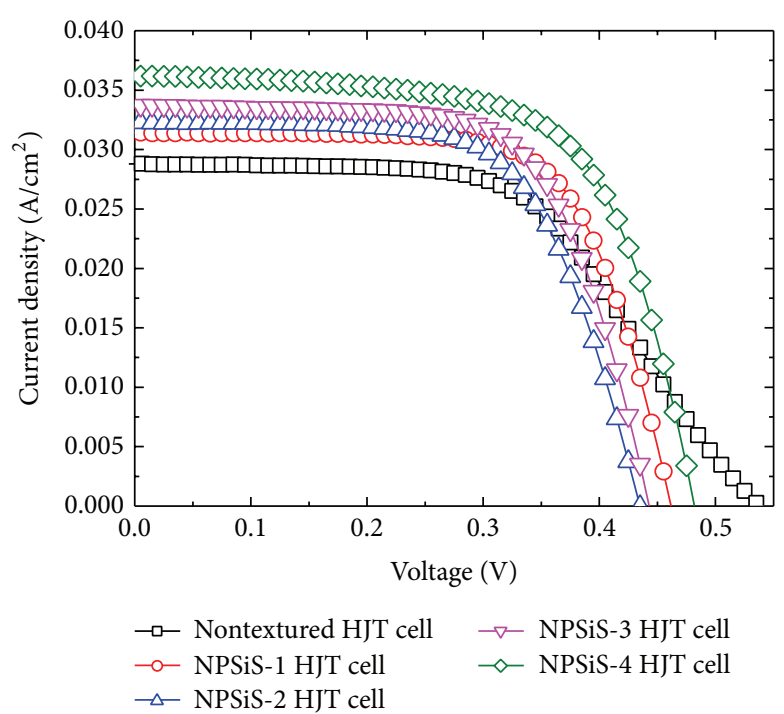

(b)

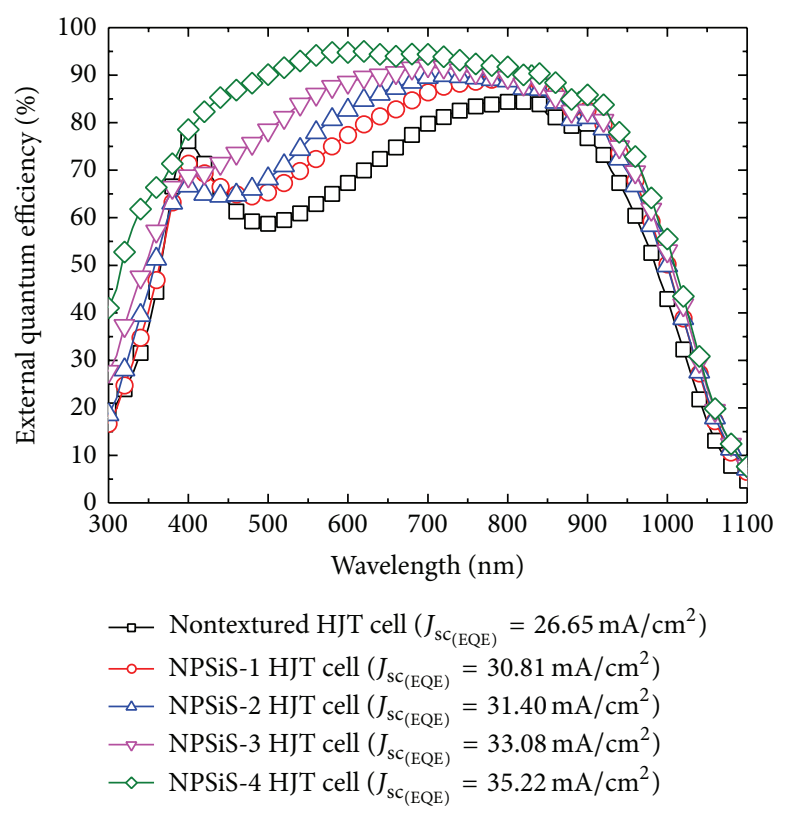

(c)

Figure 7: Measured $I$ - $V$ curves of four NPSiS-HJT cells and nontextured HJT cell: (a) dark $I$ - $V$, (b) illuminated $I-V$ (AM 1.5G condition), and (c) corresponding external quantum efficiency (EQE) characteristics.

wafer, generating more defects on its surface, increasing the leakage current of the cell, and reducing the shunt resistivity. The $V_{\text {oc }}$ values of all of the NPSiS HJT cells were therefore reduced to different degrees. This phenomenon will be investigated by treating the plasma-damaged surfaces using various methods.

\section{Conclusion}

In this work, RF magnetron sputtering was performed to fabricate silicon HJT solar cells. In the sputtering deposition process, p-type a-Si:H films were sputtered with added boron grains on the p-type c-Si target to increase the amount of dopant boron atoms in the thin films. Then, the ITO/p-type a-Si:H/n-type c-Si structure was fabricated for use in HJT solar cells, and its characteristics were measured. The $V_{\mathrm{oc}}, J_{\mathrm{sc}}$, $\mathrm{FF}$, and power conversion efficiency of the reference Si-based HJT solar cells were $537 \mathrm{mV}, 28.8 \mathrm{~mA} / \mathrm{cm}^{2}, 56.3 \%$, and $8.67 \%$, respectively.

NPSiS wafer was demonstrated effectively to improve the power conversion efficiency of HJT cells. The NPSiS-4 HJT cell efficiency was $11.4 \%$, representing an enhancement of $31.49 \%$ relative to that, $8.67 \%$, of the flat silicon HJT cell. This enhancement arose from the improvement in $J_{\mathrm{sc}}$, which 


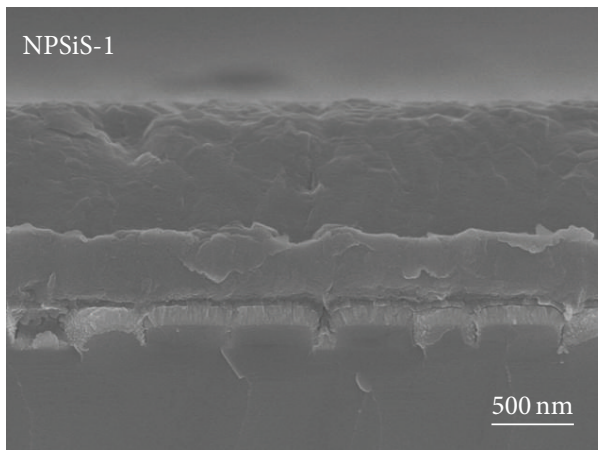

(a)

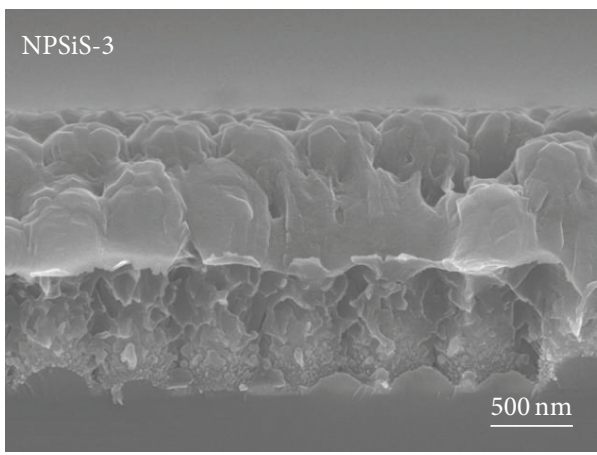

(c)

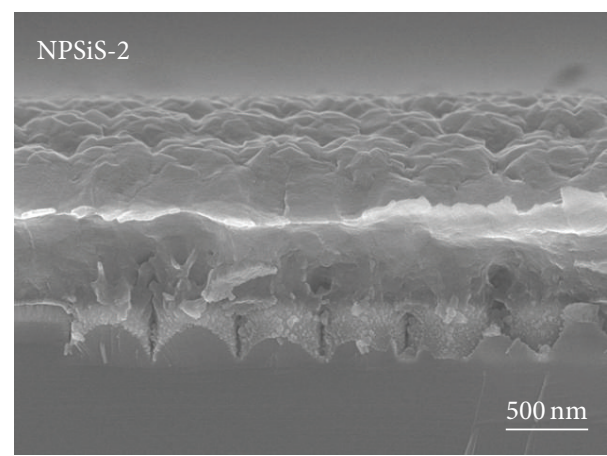

(b)

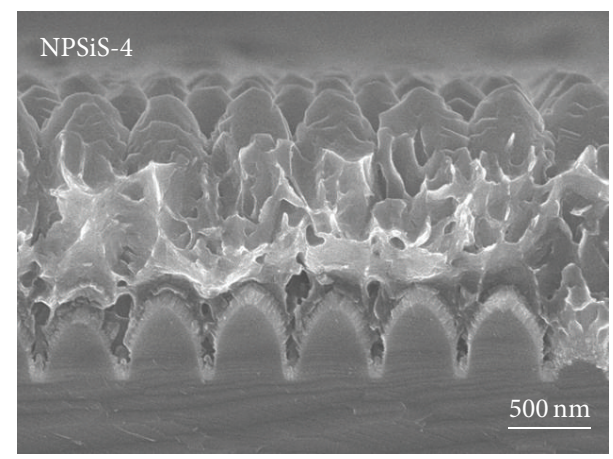

(d)

Figure 8: SEM images of metal contacts of four NPSiS HJT cells: (a) NPSiS-1 HJT cell, (b) NPSiS-2 HJT cell, (c) NPSiS-3 HJT cell, and (d) NPSiS-4 HJT cell.

increased the absorption of incident light on the surface of the NPSiS wafer, and from the improvement in FF by the increase in the surface area of the silicon, which reduced the series resistance of the NPSiS HJT cells. The dry etching process reduced the $V_{\text {oc }}$ of the NPSiS HJT solar cells. A further investigation must be undertaken to solve this problem. Based on the above results, NPSiS that is patterned using nanospheres lithography in the sputtering deposition process can be used in the low-cost fabrication of Si-based HJT solar cells.

\section{Conflict of Interests}

The authors declare that there is no conflict of interests regarding the publication of this paper.

\section{Acknowledgment}

The authors would like to thank the National Science Council of Taiwan, Taiwan, for financially supporting this research under Contract no. NSC101-2221-E-008-027-MY2.

\section{References}

[1] D. L. Staebler and C. R. Wronski, "Reversible conductivity changes in discharge-produced amorphous Si," Applied Physics Letters, vol. 31, no. 4, pp. 292-294, 1977.
[2] M. Tanaka, M. Taguchi, T. Matsuyama et al., "Development of new a-Si/c-Si heterojunction solar cells: ACJ-HIT (Artificially Constructed Junction-Heterojunction with Intrinsic Thin-layer)," Japanese Journal of Applied Physics 1: Regular Papers and Short Notes and Review Papers, vol. 31, no. 11, pp. 3518-3522, 1992.

[3] M. Tanaka, S. Okamoto, S. Tsuge, and S. Kiyama, "Development of HIT solar cells with more than $21 \%$ conversion efficiency and commercialization of highest performance hit modules," in Proceddings of the 3rd World Conference on Photovoltaic Energy Conversion, pp. 955-958, Osaka, Japan, May 2003.

[4] M. Taguchi, A. Yano, S. Tohoda et al., " $24.7 \%$ record efficiency HIT solar cell on thin silicon wafer," Journal of Photovoltaics, vol. 4, no. 1, pp. 96-99, 2014.

[5] B. Jagannathan, W. A. Anderson, and J. Coleman, "Amorphous silicon/p-type crystalline silicon heterojunction solar cells," Solar Energy Materials and Solar Cells, vol. 46, no. 4, pp. 289310, 1997.

[6] K.-S. Ji, J. Choi, H. Yang, H.-M. Lee, and D. Kim, "A study of crystallinity in amorphous Si thin films for silicon heterojunction solar cells," Solar Energy Materials and Solar Cells, vol. 95, no. 1, pp. 203-206, 2011.

[7] H. Angermann, E. Conrad, L. Korte, J. Rappich, T. F. Schulze, and M. Schmidt, "Passivation of textured substrates for a$\mathrm{Si}: \mathrm{H} / \mathrm{c}-\mathrm{Si}$ hetero-junction solar cells: Effect of wet-chemical smoothing and intrinsic a-Si:H interlayer," Materials Science and Engineering B: Solid-State Materials for Advanced Technology, vol. 159-160, pp. 219-223, 2009.

[8] M. Gharghi, E. Fathi, B. Kante, S. Sivoththaman, and X. Zhang, "Heterojunction silicon microwire solar cells," Nano Letters, vol. 12, no. 12, pp. 6278-6282, 2012. 
[9] Y. Ohmura, M. Takahashi, M. Suzuki, N. Sakamoto, and T. Meguro, "P-type doping of hydrogenated amorphous silicon films with boron by reactive radio-frequency co-sputtering," Physica B: Condensed Matter, vol. 308-310, pp. 257-260, 2001.

[10] M. M. De Lima Jr., F. L. Freire Jr., and F. C. Marques, "Boron doping of hydrogenated amorphous silicon prepared by rf-cosputtering," Brazilian Journal of Physics, vol. 32, no. 2, pp. 379$382,2002$.

[11] J.-Q. Xi, M. F. Schubert, J. K. Kim et al., "Optical thin-film materials with low refractive index for broadband elimination of Fresnel reflection," Nature Photonics, vol. 1, no. 3, pp. 176-179, 2007.

[12] G. Crotty, T. Daud, and R. Kachare, "Front surface passivation of silicon solar cells with antireflection coating," Journal of Applied Physics, vol. 61, no. 8, pp. 3077-3079, 1987.

[13] H.-W. Huang, J. T. Chu, C. C. Kao et al., "Enhanced light output of an InGaN/GaN light emitting diode with a nano-roughened p-GaN surface," Nanotechnology, vol. 16, no. 9, pp. 1844-1848, 2005.

[14] W.-C. Lee, S.-J. Wang, K.-M. Uang et al., "Enhanced light output of GaN-based vertical-structured light-emitting diodes with two-step surface roughening using $\mathrm{KrF}$ laser and chemical wet etching," IEEE Photonics Technology Letters, vol. 22, no. 17, pp. 1318-1320, 2010.

[15] D. Liang, Y. S. Kang, Y. Huo, Y. Chen, Y. Cui, and J. S. Harris, "High-efficiency nanostructured window GaAs solar cells," Nano Letters, vol. 13, no. 10, pp. 4850-4856, 2013.

[16] K.-Q. Peng, X. Wang, L. Li, X.-L. Wu, and S.-T. Lee, "Highperformance silicon nanohole solar cells," Journal of the American Chemical Society, vol. 132, no. 20, pp. 6872-6873, 2010.

[17] E. Garnett and P. Yang, "Light trapping in silicon nanowire solar cells," Nano Letters, vol. 10, no. 3, pp. 1082-1087, 2010.

[18] L. Cao, P. Fan, A. P. Vasudev et al., "Semiconductor nanowire optical antenna solar absorbers," Nano Letters, vol. 10, no. 2, pp. 439-445, 2010.

[19] S. Jeong, E. C. Garnett, S. Wang et al., "Hybrid silicon nanoconepolymer solar cells," Nano Letters, vol. 12, no. 6, pp. 2971-2976, 2012.

[20] Y. Kanamori, M. Sasaki, and K. Hane, "Broadband antireflection gratings fabricated upon silicon substrates," Optics Letters, vol. 24, no. 20, pp. 1422-1424, 1999.

[21] M. Iwaya, H. Kasugai, T. Kawashima et al., "Improvement in light extraction efficiency in group III nitride-based lightemitting diodes using moth-eye structure," Thin Solid Films, vol. 515, no. 2, pp. 768-770, 2006.

[22] H. Hlaing, X. Lu, T. Hofmann, K. G. Yager, C. T. Black, and B. M. Ocko, "Nanoimprint-induced molecular orientation in semiconducting polymer nanostructures," ACS Nano, vol. 5, no. 9, pp. 7532-7538, 2011.

[23] Y. Yang, K. Mielczarek, M. Aryal, A. Zakhidov, and W. Hu, "Nanoimprinted polymer solar cell," ACS Nano, vol. 6, no. 4, pp. 2877-2892, 2012.

[24] K. Hadobás, S. Kirsch, A. Carl, M. Acet, and E. F. Wassermann, "Reflection properties of nanostructure-arrayed silicon surfaces," Nanotechnology, vol. 11, no. 3, pp. 161-164, 2000.

[25] C.-H. Sun, P. Jiang, and B. Jiang, "Broadband moth-eye antireflection coatings on silicon," Applied Physics Letters, vol. 92, no. 6, Article ID 061112, pp. 061112-061113, 2008.

[26] T. Nakanishi, T. Hiraoka, A. Fujimoto, S. Saito, and K. Asakawa, "Nano-patterning using an embedded particle monolayer as an etch mask," Microelectronic Engineering, vol. 83, no. 4-9, pp. 1503-1508, 2006.
[27] S.-Y. Chuang, H.-L. Chen, J. Shieh et al., "Nanoscale of biomimetic moth eye structures exhibiting inverse polarization phenomena at the Brewster angle," Nanoscale, vol. 2, no. 5, pp. 799-805, 2010.

[28] C.-H. Chan, C.-H. Hou, C.-K. Huang et al., "Patterning periodical motif on substrates using monolayer of microspheres: application in GaN light-emitting diodes," Japanese Journal of Applied Physics, vol. 48, no. 2, Article ID 020212, 2009.

[29] J.-Y. Jung, Z. Guo, S.-W. Jee, H.-D. Um, K.-T. Park, and J.-H. Lee, "A strong antireflective solar cell prepared by tapering silicon nanowires," Optics Express, vol. 18, no. 19, pp. A286-A292, 2010.

[30] K. Kim, S. K. Dhungel, S. Jung, D. Mangalaraj, and J. Yi, "Texturing of large area multi-crystalline silicon wafers through different chemical approaches for solar cell fabrication," Solar Energy Materials and Solar Cells, vol. 92, no. 8, pp. 960-968, 2008.

[31] H. Angermann, W. Henrion, M. Rebien, and A. Röseler, "Wetchemical passivation and characterization of silicon interfaces for solar cell applications," Solar Energy Materials and Solar Cells, vol. 83, no. 4, pp. 331-346, 2004.

[32] C.-H. Chan, C.-H. Hou, S.-Z. Tseng et al., "Improved output power of GaN-based light-emitting diodes grown on a nanopatterned sapphire substrate," Applied Physics Letters, vol. 95, no. 1, Article ID 011110, 2009.

[33] E. Centurioni and D. Iencinella, "Role of front contact work function on amorphous silicon/crystalline silicon heterojunction solar cell performance," IEEE Electron Device Letters, vol. 24, no. 3, pp. 177-179, 2003.

[34] L. Zhao, C. L. Zhou, H. L. Li, H. W. Diao, and W. J. Wang, "Role of the work function of transparent conductive oxide on the performance of amorphous/crystalline silicon heterojunction solar cells studied by computer simulation," Physica Status Solidi A, vol. 205, no. 5, pp. 1215-1221, 2008.

[35] H. L. Chen, S. Y. Chuang, C. H. Lin, and Y. H. Lin, "Using colloidal lithography to fabricate and optimize sub-wavelength pyramidal and honeycomb structures in solar cells," Optics Express, vol. 15, no. 22, pp. 14793-14803, 2007.

[36] C.-H. Sun, P. Jiang, and B. Jiang, "Broadband moth-eye antireflection coatings on silicon," Applied Physics Letters, vol. 92, no. 6, Article ID 061112, 2008.

[37] H. Sai, H. Fujii, K. Arafune et al., "Antireflective subwavelength structures on crystalline $\mathrm{Si}$ fabricated using directly formed anodic porous alumina masks," Applied Physics Letters, vol. 88, no. 20, Article ID 201116, 2006.

[38] S.-K. Kim, J. C. Lee, S.-J. Park, Y.-J. Kim, and K. H. Yoon, “Effect of hydrogen dilution on intrinsic a-Si:H layer between emitter and Si wafer in silicon heterojunction solar cell," Solar Energy Materials and Solar Cells, vol. 92, no. 3, pp. 298-301, 2008. 

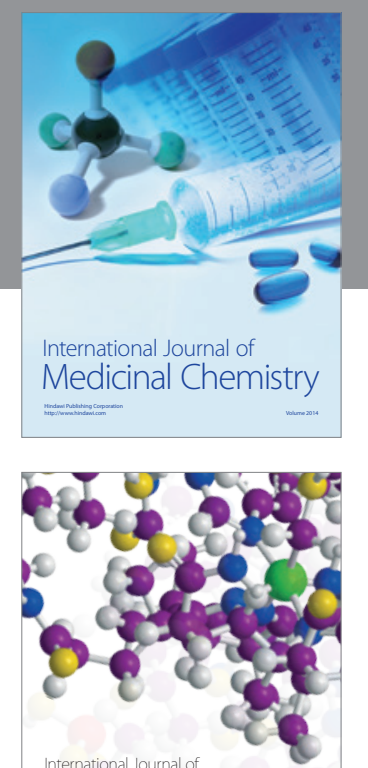

\section{Carbohydrate} Chemistry

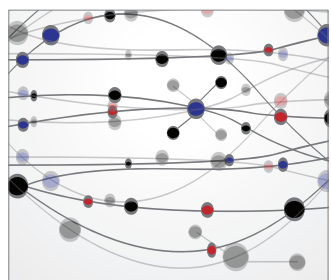

The Scientific World Journal
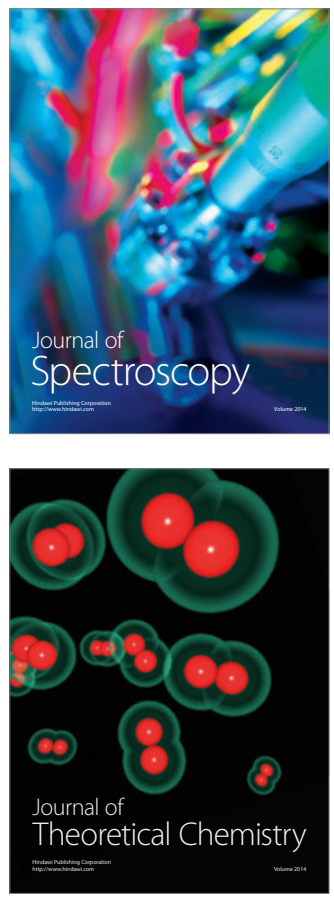
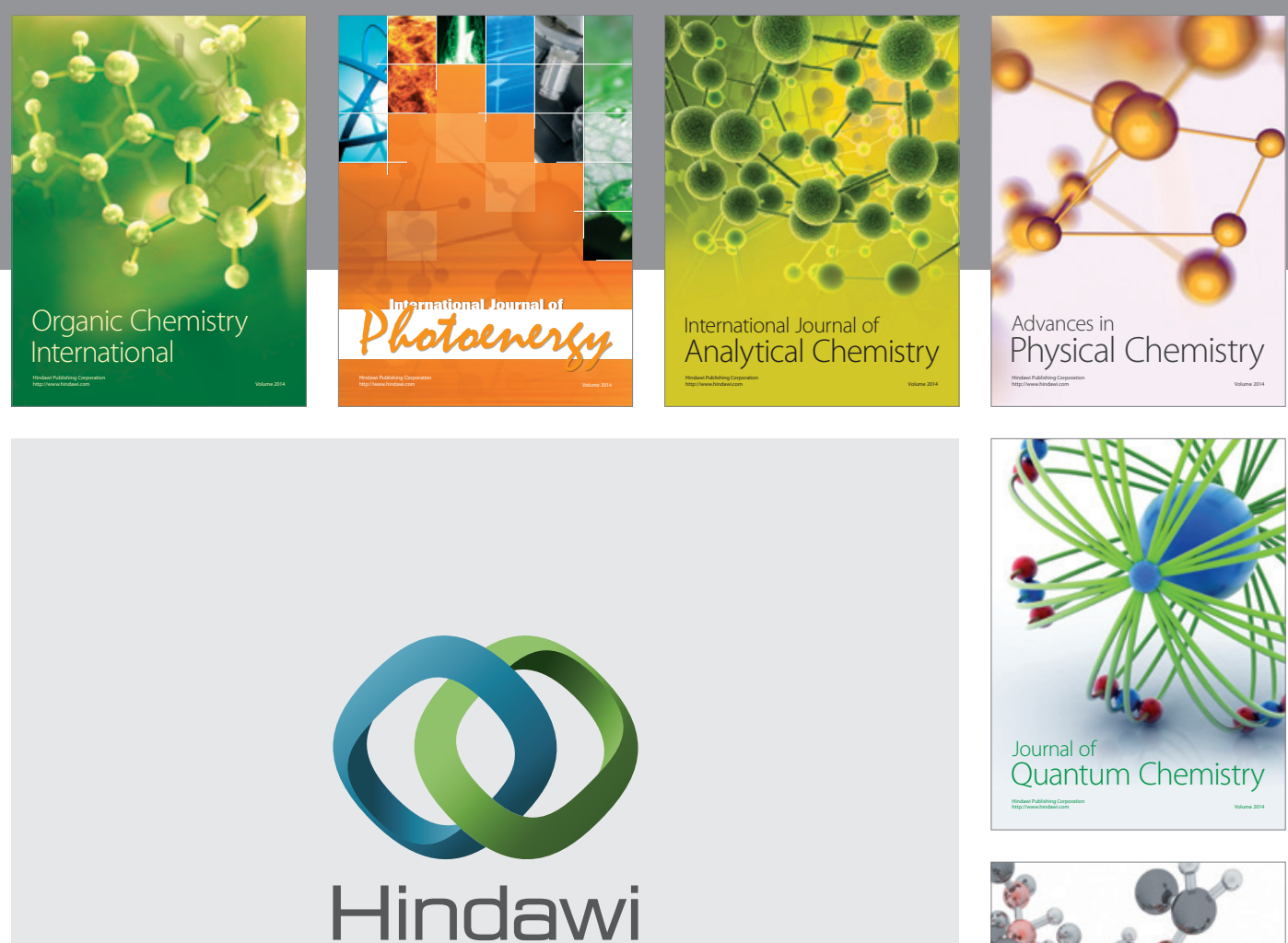

Submit your manuscripts at

http://www.hindawi.com

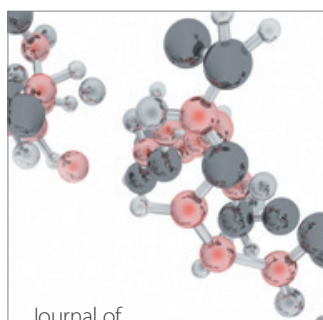

Analytical Methods

in Chemistry

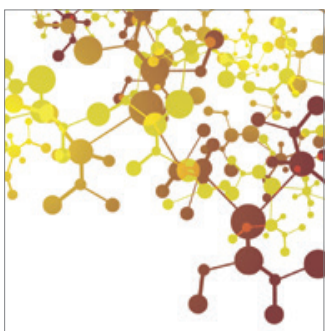

Journal of

Applied Chemistry

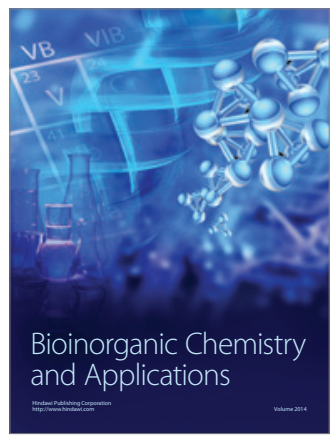

Inorganic Chemistry
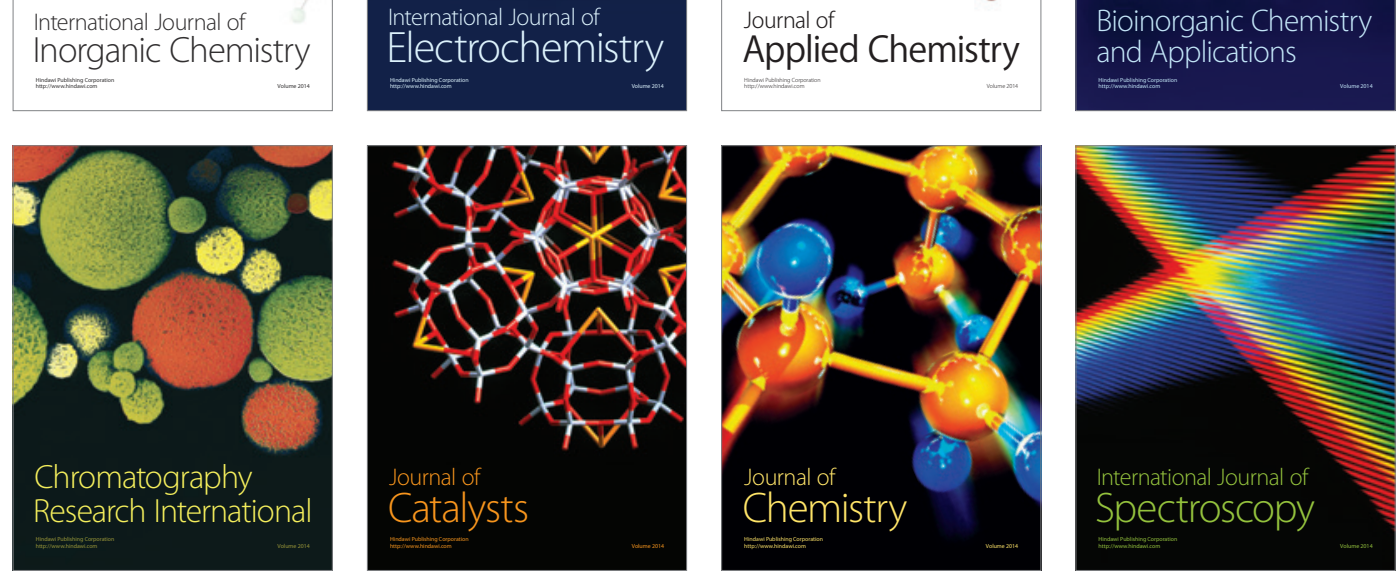